\title{
THE EFFECT OF A STANDARD EXERCISE UPON THE OXYGEN CONSUMPTION OF NORMAL, OVERWEIGHT, AND CHRONICALLY ILL INDIVIDUALS*
}

\author{
By BYRON D. BOWEN AND MABEL E. CARMER
}

(From the Buffalo General Hospital)

(Received for publication January 4, 1926)

\section{INTRODUCTION}

This work was originally undertaken eighteen months ago, with the thought that possibly a study of the oxygen consumption during a standard exercise and the length of time required for the subject to pay off his oxygen debt might be of some value in appraising the fitness of an individual. We were disappointed to find that normal individuals varied widely in their percentage of oxygen consumption during exercise, according to their surface area. However, in duplicating the tests on the first subjects studied, we found that the response to exercise was constant in the individual, indicating that the test was accurate despite the wide variation that occurred in different subjects. Because of this individual constancy, it was decided to extend the study to include individuals who were overweight and those who had miscellaneous chronic diseases.

The literature upon the effect of work upon respiratory metabolism has been so recently reviewed by Boothby and Sandiford (4) that it seems unnecessary to include an extensive consideration of it here, particularly when so little of it has a bearing on the phase of the problem to which this work pertains.

Smith (8) in an extensive study upon walking finds that in eight subjects the increase in energy expended in horizontal walking from standing varied from 0.454 to 0.618 gram-calorie for each horizontal kilogram-meter, and that variations in speed under 80 meters per minute had no effect upon the results, but above that point the expenditure of energy increased proportionately with the speed.

\footnotetext{
* Presented in abstract before the joint meeting of The Federation of American Societies for Experimental Biology, at Cleveland, Ohio, December 30, 1925.
} 
Strouse, Wang and Owen (9) report a résumé of a study of the mechanical efficiency, as measured by a bicycle ergometer, on thirteen obese, ten normal, and six thin subjects. Their figures show that the obese spend more energy on a given piece of work than the normal and that the thin people are the most efficient of the three groups. Peabody, Sturgis, Barker and Reed (7) compared the oxygen consumption and pulmonary ventilation of eleven ambulatory cardiac patients with normal subjects, during standing, and walking sixty steps. The same relative changes in the oxygen consumption and pulmonary ventilation were found in the two groups.

In the monograph by Hill and Lupton (6) upon Muscular Exercise, Lactic Acid, and Supply of Oxygen, they state, that in a moderate exercise the respiratory quotient should remain at unity, because the protein buffers of the muscle should neutralize all the lactic acid formed, so that little $\mathrm{CO}_{2}$ should be driven out. In their experiments they found that after a moderate exercise the oxygen intake would return to its resting level in six to eight minutes. Their observations, we imagine, were made with atmospheric air, while ours were made with pure oxygen so the results may not be comparable.

Benedict and Benedict (2) studied the effect of minor muscular movements upon the metabolism and found that some of them had a definite influence upon the consumption of oxygen,- - thus, fifteen movements of the arm per minute produced an increase in the metabolism of about 11 per cent, and three movements of the leg per minute caused an increase of about 13 per cent in the metabolism.

Boothby and Sandiford, whose work will be referred to later on, have shown, in a series of fourteen patients with hyperthyroidism, that they require nearly twice as much energy to perform a given piece of work as do normal persons or patients with other diseases.

\section{METHOD OF STUDY}

The subjects were all studied in the post-absorptive state, not having had food for twelve to fifteen hours. The Portable Benedict (1) apparatus was used for all the determinations. The surface area formula of DuBois and DuBois (5) was used in calculating both the basal and exercise metabolic rates. The formulas proposed by West (10) were used in the calculation of the vital capacity in percentages; the height formula being used for those who were obese or overweight, and the surface area formula for all the others. 
In the choice of a satisfactory exercise with which the Benedict Portable apparatus could be used, we thought it best to select some activity which would be comparable to walking so that it could be made as nearly automatic as possible and so that the relation of the amount of work done to the individual would be as near a constant as possible. The subject lay on his back and was required to lift his lower extremities rhythmically and alternately, so as to touch with his toes a string which was placed a given distance, corresponding to about one pace, fr im the plane on which he was lying.

TABLE 1

Normal subjects (arranged in order of weight)

\begin{tabular}{|c|c|c|c|c|c|c|c|c|c|c|c|c|}
\hline 曽 & 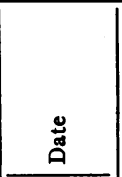 & ฒ & 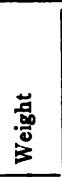 & $\begin{array}{l}\text { 葛 } \\
\text { 悹 }\end{array}$ & 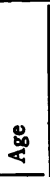 & 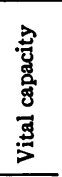 & 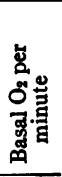 & 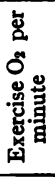 & $\underset{\sim}{\ddot{n}}$ & 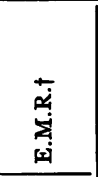 & 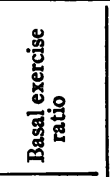 & 存 \\
\hline & & & kg. & $\mathrm{cm}$. & & $\begin{array}{l}\text { per } \\
\text { cent } \\
S . A .\end{array}$ & $c c$. & $c c$. & per cent & per cent & & min-s \\
\hline 3 & $|12-10-24|$ & M. & 60.7 & 168 & 18 & 88 & 302 & 512 & +12 & +99 & $1: 1.77$ & 3 \\
\hline 28 & $12-11-24$ & M. & 59.8 & 167.5 & 25 & 98 & 243 & 456 & -3 & +92 & $1: 1.98$ & 3 \\
\hline 20 & $1-10-25$ & & 60.4 & 167.5 & 25 & 103 & 201 & 390 & -19 & +62 & $1: 2.00$ & 3 \\
\hline 23 & $|12-4-24|$ & F. & 58 & 162 & 19 & 105 & 223 & 535 & -3 & +141 & $1: 2.53$ & 6 \\
\hline 23 & $2-13-25$ & & 59.6 & 162 & 19 & 104 & 205 & 496 & -15 & +118 & $1: 2.56$ & 6 \\
\hline 24 & 2- 5-25 & M. & 56.7 & 175 & 26 & 117 & 218 & 446 & -15 & +84 & $1: 2.16$ & 4 \\
\hline & $2-12-25$ & & 58.2 & 175 & 26 & 117 & 216 & 441 & -17 & +77 & $1: 2.13$ & 4 \\
\hline & $12-6-24$ & F. & 55.6 & 169 & 28 & 95 & 225 & 503 & -3 & +127 & $1: 2.34$ & \\
\hline 21 & $2-14-25$ & & 54.5 & 169 & 28 & 96 & 220 & 520 & -3 & +137 & $1: 2.44$ & 4 \\
\hline 56 & $12-9-25$ & F. & 53.1 & 168 & 27 & 89 & 230 & 500 & -1 & +121 & $1: 2.23$ & 3 \\
\hline 10 & $2-10-25$ & M. & 51.7 & 164 & 16 & 96 & 258 & 663 & +1 & +170 & $1: 2.67$ & 4 \\
\hline & $2-14-25$ & & 52.3 & 164 & 16 & 97 & 265 & 641 & +3 & +161 & $1: 2.53$ & 5 \\
\hline
\end{tabular}

* B.M.R.-basal metabolic rate expressed in per cent above or below 100 .

† E.M.R.-exercise metabolic rate expressed in per cent above or below 100 .

The subject's basal metabolism was first determined after a period of rest, usually at least thirty minutes, allowing a sufficient time for the pulse rate and blood pressure to become stabilized. No subjects having any degree of fever were studied. The apparatus was tested for leakage before each experiment by placing a 100 gram weight on top of the spirometer which was filled with oxygen, and checking the reading at the end of six minutes. We required that the oxygen consumed in six minutes should check another period within $20 \mathrm{cc}$. After the 
TABLE 2

Obese and overweight subjects (arranged in order of weight)

\begin{tabular}{|c|c|c|c|c|c|c|c|c|c|c|c|c|}
\hline 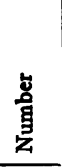 & 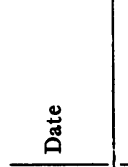 & ॐ & 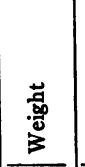 & 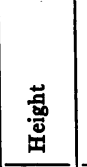 & $\stackrel{\infty}{\&}$ & 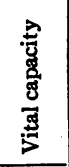 & 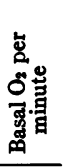 & 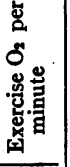 & 㟧 & $\sum_{\dot{j}}^{\dot{a j}}$ & 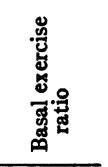 & 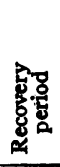 \\
\hline \multirow{3}{*}{$32 *$} & & \multirow{3}{*}{ F. } & kg. & $\mathrm{cm}$. & & $\begin{array}{c}\text { per } \\
\text { cent } \\
\text { height }\end{array}$ & $c c$. & $c c$. & per cent & per cent & & $\begin{array}{l}\text { min- } \\
\text { utes }\end{array}$ \\
\hline & $6-20-25$ & & 151.5 & 160.5 & 34 & 75 & 352 & 692 & +11 & +128 & $1: 2.05$ & 3 \\
\hline & $6-30-25$ & & 147.7 & 160.5 & 34 & 75 & 335 & 688 & +6 & +128 & $1: 2.15$ & 3 \\
\hline 47 & $4-7-25$ & F. & 137.5 & 164 & 54 & 82 & 268 & 675 & -14 & +125 & $1: 2$ & 4 \\
\hline 34 & $3-2-25$ & F. & 130.2 & 166 & 16 & 124 & 292 & 687 & -20 & +97 & $1: 2.46$ & 4 \\
\hline $2 \dagger$ & $\mid 12-10-24$ & F. & 119 & 172 & 48 & 73 & 248 & 430 & -20 & +45 & $1: 1.81$ & \\
\hline 15 & $2-27-25$ & F. & 116.6 & 159 & 30 & 81 & 263 & 553 & -16 & +92 & $1: 2.29$ & 4 \\
\hline 54 & $11-27-25$ & F. & 109.1 & 157 & 11 & 83 & 252 & 602 & -27 & +83 & $1: 2.50$ & 4 \\
\hline 17 & -25 & F. & $|106.2|$ & 156 & 46 & 99 & 272 & 520 & +1 & +98 & & 3 \\
\hline $48^{*}$ & $5-22-25$ & F. & 88 & 161 & 85 & 84 & 232 & 547 & -14 & +116 & .51 & 3 \\
\hline 2 & & M. & 85.3 & 167 & 33 & 91 & 268 & 608 & $\cdot-8$ & +1 & & 4 \\
\hline & $2-14-25$ & & 85 & 167 & 33 & 91 & 263 & 597 & -11 & +112 & $1: 2.38$ & 5 \\
\hline 40 & $12-19-24$ & F. & 84 & 147 & 34 & 85 & 272 & 820 & +10 & +255 & $1: 3.23$ & 6 \\
\hline 18 & $22-17-25$ & F. & 82.6 & 158 & 27 & 107 & 240 & 622 & -8 & +151 & $1: 2.73$ & 4 \\
\hline $31^{*}$ & $4-11-25$ & M. & 81.7 & 166 & 52 & 84 & 235 & 672 & -13 & +166 & $1: 3.05$ & 3 \\
\hline $44^{*}$ & $-10-25$ & F. & 80.7 & 149 & 64 & 74 & 232 & 480 & +1 & +116 & 18 & 3 \\
\hline $50^{*}$ & $3-28-25$ & F. & 80.5 & 163 & 29 & 107 & 242 & 622 & -7 & +137 & $1: 2$ & 4 \\
\hline 13 & $|12-4-24|$ & F. & 78.5 & 163.5 & 34 & 106 & 245 & 455 & -1 & +90 & $1: 1.91$ & \\
\hline 10 & $2-11-25$ & & 77.6 & 163.5 & 34 & 113 & 240 & 467 & -7 & +89 & $1: 2.03$ & 4 \\
\hline 25 & $|12-9-25|$ & F. & 72.8 & 163.3 & 28 & 86 & 242 & 555 & -5 & +127 & $1: 2$ & 7 \\
\hline $53 \ddagger$ & $\mid 11-23-25$ & F. & 69.6 & 167.5 & 34 & 110 & 195 & 447 & -21 & +184 & $1: 3.56$ & 6 \\
\hline 55 & $|12-5-25|$ & F. & 69.1 & 157.5 & 12 & 86 & 270 & 550 & -5 & +113 & $1: 2.24$ & 3 \\
\hline $38^{*}$ & $|12-6-24|$ & $\mathrm{F}$. & 68.7 & 163 & 17 & 86 & 252 & 550 & -7 & +112 & $1: 2.28$ & 5 \\
\hline 27 & $|12-2-24|$ & F. & 67 & 163 & 24 & 98 & 240 & 692 & +1 & +149 & $1: 2.47$ & \\
\hline & $2-4-25$ & & 67 & 163 & 24 & 101 & 242 & 585 & +1 & +159 & $1: 2.56$ & 4 \\
\hline 26 & $|12-3-24|$ & F. & 60.7 & 164 & 24 & 85 & 232 & 47.5 & +1 & +114 & $1: 2.12$ & \\
\hline 20 & $|2-3-25|$ & & 61.5 & 164 & 24 & 87 & 237 & 467 & +3 & +111 & $1: 2.05$ & 6 \\
\hline
\end{tabular}

* Diabetic.

$\dagger$ Anemic type of obesity with diabetes. Patient fatigues so that only one six-minute exercise observation could be made.

† "Breeches" type of obesity.

basal metabolism was satisfactorily determined, the oxygen consumption during exercise was determined in the following way: A string was placed across the foot of the cot 30 inches above the surface so that the subject could easily touch it with his toes as his lower extremity swung through the arc. A metronome was placed 
near the foot of the cot and set so that it clicked sixty-six times per minute. The subject was then instructed to touch the string with the toe at the first beat of the metronome and to touch the bed with the heel at the second beat, alternating the lower extremities. In other words, each lower extremity was lifted so that the toe touched the string about seventeen times per minute. It appeared that this exercise, to the well-beaten time, became, after a moment's practise, very rhyth-

TABLE 3

Diabetic subjects (arranged in order of weight)

\begin{tabular}{|c|c|c|c|c|c|c|c|c|c|c|c|c|}
\hline 竞 & 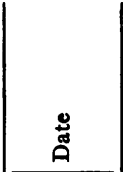 & હ゙્ & 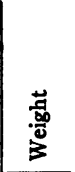 & 壱 & $\stackrel{8}{4}$ & 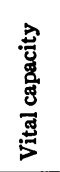 & 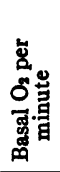 & 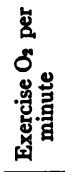 & & 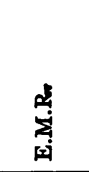 & 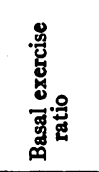 & 弯 \\
\hline \multirow{3}{*}{32} & & \multirow{3}{*}{ F. } & kg. & $\mathrm{cm}$. & & $\begin{array}{c}\text { per } \\
\text { cent } \\
S . A .\end{array}$ & cc. & cc. & per cent & per cent & & min- \\
\hline & $6-20-25$ & & 151.5 & 160.5 & 34 & 75 & 352 & 692 & +11 & +128 & $1: 2.05$ & 3 \\
\hline & $6-30-25$ & & 147.7 & 160.5 & 34 & 75 & 335 & 688 & +6 & +128 & $1: 2.15$ & 3 \\
\hline 2 & $12-10-24$ & F. & 119 & 172 & 48 & 73 & 248 & 430 & -20 & +45 & $1: 1.81$ & \\
\hline 48 & $5-22-25$ & F. & 88 & 161 & 35 & 84 & 232 & 547 & -14 & +116 & $1: 2.51$ & 3 \\
\hline 31 & $4-11-25$ & M. & 81.7 & 166 & 52 & 84 & 235 & 672 & -13 & +166 & $1: 3.05$ & 3 \\
\hline 44 & $3-10-25$ & F. & 80.7 & 149 & 64 & 74 & 232 & 480 & +1 & +116 & $1: 2.18$ & 3 \\
\hline 50 & $3-28-25$ & F. & 80.5 & 163 & 29 & 107 & 242 & 622 & -7 & +137 & $1: 2.55$ & 4 \\
\hline 43 & $3-19-25$ & $\mathbf{F}$. & 73 & 164.5 & 37 & 81 & 268 & 677 & +2 & +179 & $1: 2.74$ & 3 \\
\hline 51 & $3-31-25$ & M. & 72.7 & 169 & 19 & 99 & 252 & 550 & -13 & +99 & $1: 2.40$ & 3 \\
\hline 38 & $12-6-24$ & F. & 68.7 & 163 & 17 & 86 & 252 & 550 & -7 & +112 & $1: 2.28$ & 5 \\
\hline 12 & $1-23-25$ & F. & 66.2 & 170 & 57 & 85 & 198 & 417 & -14 & +88 & $1: 2.19$ & 4 \\
\hline 36 & $3-6-25$ & M. & 61 & 170.5 & 29 & 109 & 215 & 438 & -15 & +76 & $1: 2.07$ & 3 \\
\hline 41 & $12-5-24$ & M. & 60.8 & 164 & 65 & 68 & 248 & 422 & +7 & +91 & $1: 1.77$ & 4 \\
\hline 35 & $3-2-25$ & M. & 60.7 & 157.5 & 31 & 109 & 232 & 528 & -4 & +128 & $1: 2.38$ & 3 \\
\hline 52 & $3-24-25$ & M. & 58.9 & 161.5 & 38 & 91 & 228 & 658 & -6 & +181 & $1: 2.99$ & 3 \\
\hline 46 & 3- 5-25 & F. & 57.9 & 160 & 53 & 100 & 227 & 383 & +6 & +88 & $1: 1.77$ & 3 \\
\hline 20 & $2-24-25$ & M. & 57.7 & 176 & 46 & 103 & 215 & 453 & -15 & +89 & $1: 2.22$ & 4 \\
\hline 49 & $4-8-25$ & F. & 57.2 & 150.5 & 58 & 82 & 198 & 478 & -1 & +149 & $1: 2.51$ & 3 \\
\hline 45 & $3-4-25$ & M. & 55.7 & 177 & 26 & 104 & 215 & 520 & -16 & +112 & $1: 2.52$ & 3 \\
\hline 16 & $2-28-25$ & F. & 55.5 & 161 & 51 & 96 & 210 & 430 & +2 & +118 & $1: 2.13$ & 2 \\
\hline 42 & $3-18-25$ & M. & 48.2 & 164.5 & 26 & 110 & 275 & 763 & +23 & +253 & $1: 2.87$ & 4 \\
\hline 42 & $12-10-25$ & & 52.5 & 164.5 & 26 & 95 & 252 & 670 & +14 & +218 & $1: 2.78$ & 4 \\
\hline
\end{tabular}

mical and easy for the large majority of the subjects. As soon as the subject got well into the swing of this exercise, the spirometer reading was taken by the Emmes method, and it was taken again at the end of the six minutes when the subject was instructed to stop the exercise. A three-minute rest period was then given with the subject detached from the mouthpiece. Another six-minute period was then run in the same manner at the end of which, however, the subject was not detached from the apparatus but allowed to breathe oxygen after the exercise 
was stopped. The readings were then taken every minute until the reading for one minute corresponded within a few cubic centimeters of the basal oxygen consumption for one minute.

The pulse was counted every five minutes during the rest period before the basal metabolism was taken, and before, once during, and after each exercise period.

The calculations were all based upon a universal respiratory quotient of $\mathbf{0 . 8 2}$ during rest, and of unity during exercise. It is probable that the exact respiratory quotient lies somewhere between those two figures, and it certainly is improbable, judging from the work of Hill, and Benedict and Cathcart (3), that such a moderate exercise would give a respiratory quotient over unity. In any event the difference in exercise metabolism, whether figured with a respiratory quotient of $\mathbf{0 . 8 2}$ or unity, would usually be less than 5 per cent, which is negligible.

The data obtained are presented in tabular form.

\section{DISCUSSION}

Seventy-one observations on the metabolism during exercise were made on fifty-six subjects and in fifty-five of them the periods checked within $160 \mathrm{cc}$; in the remaining sixteen, the difference was slightly more than this. However, of the fifty-five who did check within $160 \mathrm{cc}$., many checked within $40 \mathrm{cc}$. and a few exactly.

Many of the subjects complained of slight fatigue following both of the periods of exercise. However, very few experienced moderate fatigue, and only one, subject 2, an individual with diabetes and obesity, had excessive fatigue so that she did not care to go through the second exercise period. It is noteworthy, that with this subject we obtained about the lowest percentage increase in metabolism during exercise. All of the other subjects had sufficiently recovered by the end of the three-minute rest period following the first exercise to go through the second period willingly.

Of course, it is obvious that the amount of work done by each individual is different and that it is impossible to quantitate the amount of this work. However, the length and weight of the lower extremity bear a more or less constant ratio to the length and weight of the trunk so that the amount of energy expended is relative to the individual. The results of the increase in metabolism produced by the exercise must then be expressed in percentages above the normal basal metabolic rate, which has been computed by the surface area formula, so that they will be comparable. Had we used a measurable 


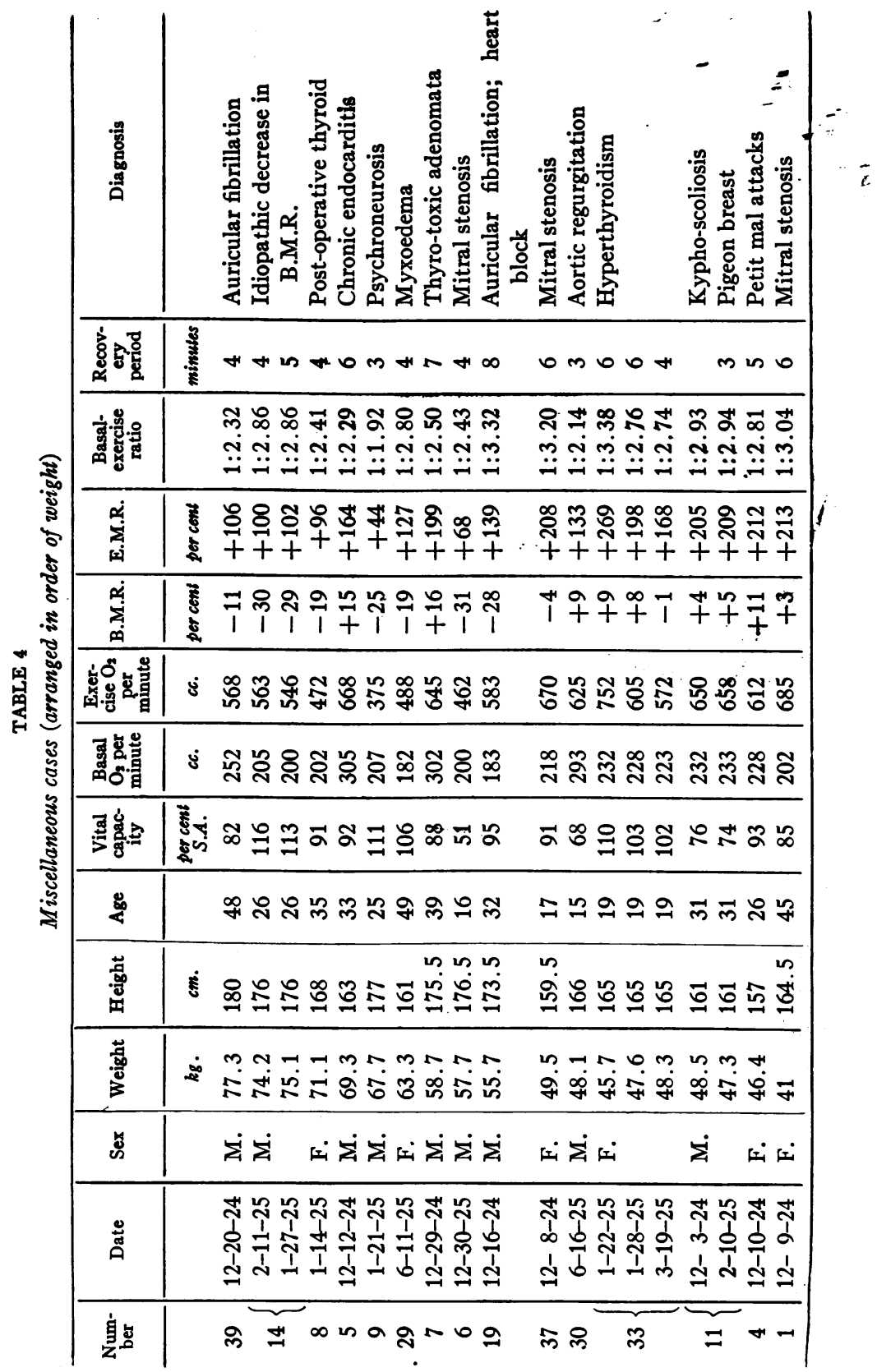


amount of work such as lifting a weight through a specified distance there would also have been inconstant factors which are unmeasurable such as the relation of the individual to the amount of work, and the energy consumed by the part of the body which was selected to move that weight.

In going over the data that have been presented in the tables it is evident that the large variation in oxygen consumption, both absolute and relative, during this standard exercise, in different individuals, makes any analysis or appraisal extremely difficult. This variation is, no doubt, attributable to many indeterminate factors such as possibly, fitness of the individual; temperament, and unequal ratios between the weight and length of the lower extremity to the weight and length of the trunk. Nevertheless, we feel that the energy expended in performing his exercise would be, in general, comparable to the work done while the subject was walking at the same rate and with the same pace.

It is quite evident from the tables, that the rate of the basal metabolism usually predetermines to some extent the rate of the oxygen consumption during exercise; those with a low basal metabolism, even though they were not definitely abnormal, showed a tendency to consume less oxygen during exercise, and on the other hand, those having even a slight increase in the basal metabolism usually consumed relatively more oxygen during activity. There are, however, a few notable exceptions to this observation: for instance subject 19, who had chronic myocarditis, auricular fibrillation, and at times, heart block, without cardiac failure, had a basal metabolism of minus 28 per cent while his metabolism during exercise was plus 139 per cent and his basal exercise ratio was 1:3.32; it is of interest, however, to note that he required eight minutes to return after exercise to his basal metabolic rate. Subject 53, who had recently developed a "breeches" type of obesity, had a basal metabolism of minus 21 per cent, but an exercise metabolism of plus 184 per cent; this probably is to be expected because of the relatively increased weight of the lower extremities. Furthermore, the accuracy of this observation is borne out by the fact that in the fourteen subjects on whom we were able to get duplicate observations, and on one, subject 33, on whom triplicate observations were made, the oxygen consumption during exercise 
checked very well with the previous determination if the basal metabolism did. Four subjects, 23, 33, 42 and 28, had a lower oxygen consumption at the second test which corresponded proportionately to the lower basal metabolism which they manifested at the same time. Subject 33 showed the clinical manifestations of hyperthyroidism without any marked increase in the basal metabolic rate. Her oxygen consumptions during exercise were plus 269 and plus 198

TABLE 5

Condensed data on fourteen subjects upon whom duplicate observations were made

\begin{tabular}{|c|c|c|c|c|c|c|}
\hline \multirow{2}{*}{ Subject } & \multicolumn{2}{|c|}{ First test } & \multicolumn{2}{|c|}{ Second test } & \multicolumn{2}{|c|}{ Basal-exercise ratio } \\
\hline & B.M.R. & E.M.R. & B.M.R. & E.M.R. & First test & Second test \\
\hline & per cons & per cont & per cont & per cout & & \\
\hline 28 & 97 & 192 & 81 & 162 & $1: 1.97$ & $1: 2.0^{*}$ \\
\hline 33 & 99 & 268 & 108 & 298 & $1: 2.74$ & $1: 2.76$ \\
\hline 23 & 97 & 244 & 85 & 218 & $1: 2.53$ & $1: 2.56$ \\
\hline 42 & 123 & 353 & 114 & 318 & $1: 2.87$ & $1: 2.78$ \\
\hline 24 & 85 & 184 & 87 & 177 & $1: 2.16$ & $1: 2.13$ \\
\hline 21 & 97 & 227 & 97 & 237 & $1: 2.34$ & $1: 2.44$ \\
\hline 10 & 101 & 270 & 103 & 261 & $1: 2.67$ & $1: 2.53$ \\
\hline 32 & 111 & 228 & 106 & 228 & $1: 2.05$ & $1: 2.15$ \\
\hline 22 & 92 & 215 & 89 & 212 & $1: 2.34$ & $1: 2.38$ \\
\hline 13 & 99 & 190 & 83 & 189 & $1: 1.91$ & $1: 2.03$ \\
\hline 27 & 101 & 249 & 101 & 259 & $1: 2.47$ & $1: 2.56$ \\
\hline 26 & 101 & 214 & 103 & 211 & $1: 2.12$ & $1: 2.05$ \\
\hline 14 & 70 & 200 & 71 & 202 & $1: 2.86$ & $1: 2.86$ \\
\hline 11 & 104 & 305 & 105 & 309 & $1: 2.93$ & $1: 2.94$ \\
\hline
\end{tabular}

* Example: In the ratio 97:192::81:162 the product of the means $(15,552)$ very nearly equals the product of the extremes $(15,714)$. The ratios are determined by dividing the actual exercise rate by the actual basal rate, thus $\frac{192}{97}$ equals 1.978.; therefore the ratio is $1: 1.978$.

per cent respectively, with a six-day period of rest intervening. About six weeks following a thyroidectomy, her basal metabolic rate had dropped to minus 1 per cent and her exercise rate had dropped to plus 169 per cent. The condensed data from the fourteen subjects upon whom duplicate observations were made are presented in table 5. The first four subjects were the only ones who showed any essential change in their basal and exercise metabolism. It will be noted that in each case the product of the means almost exactly corresponds to 
the product of the extremes, and that the ratios on the first and second tests were about equal, even though the results of the metabolism determinations varied.

Upon critical examination of the results reported on the cost of work in a series of five normal subjects and eighteen patients with miscellaneous diseases studied by Boothby and Sandiford, it will be seen that those having basal metabolic rates lower than the normal standard required fewer calories for each kilogram-meter, and on the other hand, those having higher basal metabolic rates required more, with the prominent exception of the three patients with leukaemia who had a definite increase in metabolism but a normal respone to exercise, and one case of myxoedema whose metabolism was low during rest but slightly elevated during activity, as was observed in our case. These authors, also, made repeated observations on one case of exophthalmic goitre before and after thyroidectomy, during basal conditions and while walking on a treadmill taking 24 to 30 steps per minute. Upon analysis of these data it is remarkable that the basal exercise ratio remained at about $1: 2$ during the many observations even though the basal metabolic rate varied from plus 59 per cent before operation to pfits 7 per cent afterwards, and the metabolic rate during exercise varied from plus 221 per cent before to plus 108 per cent sixteen days afterwards.

In analyzing the basal-exercise ratios of our series, it was found that the average of the ratios for the twenty subjects who were below or of normal weight was 1:2.31 and the average of the twenty-one who were overweight or obese was nearly identical-1:2.45. The basalexercise ratios of the fourteen subjects on whom repeated experiments were done agreed within a small decimal, even though the basal metabolic rate had changed appreciably as it had in four of the subjects. In subject 33, a case of mild hyperthyroidism, however, the ratios of the first and second tests did not agree, but the results of the second and third readings did. In this case there was a period of six days rest between the first and second tests and a thyroidectomy between the second and third. In view of these findings, and the wide variation that occurred in the basal exercise ratios of all subjects, it is at least suggested that all people have a rather individual response 
to effort which tends to bear a more or less constant relation to their basal metabolic rate.

It has been the experience of one of us (B. D. B.) and of many other observers, that the caloric value of the diet does not play as important a rôle in the gain or loss of weight as one might expect; thus some patients fail to gain weight on high diets, and, on the other hand, some obese people do not respond to surprisingly low diets, even though they have been under strict hospital supervision. The present study of the response to exercise does not clarify this phenomenon. Subject 31 , for instance, an active man with diabetes, who received a diet of 1900 calories and 20 units of insulin daily for the past three years, during which time he gained 20 kilograms in weight, had an exercise metabolism of plus 166 per cent and a basal-exercise ratio of 1:3.05. Our observations appear to be further proof of the futility of estimating a patient's diet by adding a certain percentage to his basal calories to provide for his activities.

It is unfortunate that we have not a larger group of individuals who could be classified as strictly normal with regard to their weight, height, basal metabolism and general health-only seven can be included in this group. It will be noted that the highest difference in the percentages of oxygen consumption for these subjects varied from plus 84 to plus 170 per cent. However, in the obese and overweight group, there are six individuals who in our opinion, are classified as overweight. The response to the exercise in this small group was fairly constant as will be noted from table 2 , with the exception of subject 53 whose accumulation of fat was almost entirely confined to the lower extremities.

Of the five diabetic patients who were definitely thin $(52,20,45$, 16 and 42 ) there is a variation in the exercise metabolism from plus 89 per cent to plus 253 per cent, which is somewhat relative, however, to the basal metabolic rate. We were particularly interested in the findings of this group because, with the exception of subject 20, their diabetes had been under control for some time and they had been on rather high diets. They had, for some reason, failed to gain weight in proportion to the caloric value of their diets as other patients had done. This apparently could not be explained on the basis of a high 
oxygen consumption, especially when we consider subject 42 who had the highest metabolism and who had gained the most weight, increasing from 48.2 to $52.5 \mathrm{~kg}$. in seven months, with a slight decrease in both his basal and exercise metabolic rates.

The average rate of the metabolism determinations during exercise of the twenty diabetic and normal subjects who were of normal weight was 121.9 per cent and the average rate of the twenty-one obese and overweight subjects, both diabetic and non-diabetic, was 124.4 per cent. It then does not appear that weight is a prominent factor in bringing about variations in oxygen consumption during exercise: in fact obese individuals seem to use about as much energy in proportion to their surface area as do normal individuals.

The subjects composing the obese and overweight group do not appear to have such wide variations in their response to exercise as was demonstrated in the other groups. Subject 40 , however, is an exception. This patient was the only one who because of her short lower extremities had difficulty in reaching the string and experienced considerable fatigue as the result of the effort. Her oxygen consumption during exercise was considerably increased as was her recovery period after the exercise. It is quite possible that in this case the slight increase in the basal metabolism (plus 10 per cent) together with the extra effort might have contributed somewhat to the high exercise metabolic rate. It is not our belief, however, that differences in the ease with which the string could be reached by the toes was a common cause of variations in the response to the exercise. Subject 44, also had short lower extremities but her exercise metabolic rate was plus 116 per cent.

Subject 11 was taken out of the normal group because he was a thin, physically inferior, individual with a kypho-scoliosis and a pigeon breast. The vital capacity of his lungs was also considerably diminished considering his surface area-76 per cent. It will be noted that the ratios of his basal and exercise oxygen consumption were, upon two occasions, 1:2.93 and 1:2.94 respectively. His recovery period was normal-three minutes-probably because his circulation was adequate.

Subject 14, apparently was normal in every respect except that his metabolic rate was consistently and abnormally diminished. His 
basal-exercise oxygen ratio, however, was higher than the average$1: 2.86$. Subject 9 , could not be satisfactorily diagnosed, but he was considered a case of psychoneurosis. It is of interest that, although he consumed relatively little oxygen during exercise he likewise required a correspondingly small amount during rest, and had a basalexercise ratio of 1:1.92 which is less than the average for normal individuals. One case of myxoedema, which was of five years standing, showed a ratio of $1: 2.8$.

This exercise did not produce any striking increase in the pulse rate with the exception that, as would be expected, the cardiac and hyperthyroidism patients consistently showed an increase of about fifteen beats. The majority of the other subjects did not show an increase in the pulse rate of over six beats, while a few increased up to twelve. No observations were made on the length of time required for the pulse rate to return to its basal rate. Records of the vital capacities on all subjects have also been recorded, but so far as we could determine, no consistent correlation could be made.

There are included in the miscellaneous group, seven cases of heart disease, mostly with valvular lesions, who had but slight heart failure without marked decrease in the vital capacity of the lungs, with the exception of subjects 6 and 30 . In four of these cases $(5,19,37$, and 1$)$ there appeared to be an increase in the oxygen consumption during exercise considerably above what we had found in the other groups. It may be significant that the recovery periods of these four were found to be longer than we observed in other patients, which probably was a manifestation of their inadequate circulation. This corresponds somewhat to the observations of Peabody et al. who found that the return to normal of the minute-volume of the respiration and heart rate were delayed in cardiac patients following exercise as compared to normal individuals. The recovery to a normal resting oxygen consumption is probably dependent upon the same phenomena as the return to a normal pulmonary ventilation. Similarly we observed the same slight delay in the recovery period in two cases of mild hyperthyroidism.

\section{SUMMARY}

The individuals composing all the groups showed a rather wide variation in their response to exercise as far as oxygen consumption 
was concerned. These are probably dependent upon factors, which, without present methods of study, are beyond our reach, and possibly are related only to the individual. Yet, despite this variation the averages of the exercise metabolism in two groups-those who were thin or of normal weight and those who were obese or overweightagreed very closely, 121.9 and 124.4 per cent above the basal rate, respectively. This would indicate that it costs the overweight individual absolutely more and relatively just as much energy to move his lower extremities as it does the individual who is thin, or of normal weight.

As far as our observations could lead us, it appears that the basal metabolic rate was the most influential single factor in determining the amount of oxygen used during the exercise. The evidence points to the probability that each person has an individual rate of oxygen consumption during exercise and that his basal-exercise metabolism ratio is constant even though his basal metabolic rate should change.

The observations upon the length of time required for the subjects to pay off their oxygen debt after exercise suggest that such observations might be of value in the study of cardiac patients, in which group we found the recovery period to be quite uniformly prolonged.

While there was close agreement in the percentage increase of the exercise metabolism in the various groups, there was usually such a wide individual variation that the study has not yielded as much information with regard to a standard response as was hoped. Possibly with refinements of study and closer analysis of the subjects, from all points of view, the test might be helpful.

\section{BIBLIOGRAPHY}

1. Benedict, Francis G.: Boston Med. and Surg. Jour., 1918, clxxxviii, 20. A Portable Respiration Apparatus for Clinical Use.

2. Benedict, Francis G., and Benedict, Cornelia Golay: Extrait du Bullétin de la Société Scientifique d'Hygiene Alimentaire, 1924, xii, 8. Influence sur le metabolism de la position du corps et des moindres mouvements musculaires.

3. Benedict, F. G., and Cathcart, E. P.: Carnegie Inst. Wash. Pub. No. 187, 1913. Muscular Work. A Metabolic Study with. Special Reference to the Efficiency of the Human Body as a Machine.

4. Boothby, Walter M., and Sandiford, Irene: Physiological Reviews, 1924, iv, 1. Basal Metabolism. 
5. DuBois, Delafield, and DuBois, Eugene F.: Arch. Int. Med., 1916, xvii, 863. A Formula to Estimate the Approximate Surface Area if Height and Weight be Known.

6. Hill, A. V., and Lupton, Hartley: Quart. Jour. Med., 1923, xvi, 135. Muscular Exercise, Lactic Acid, and the Supply and Utilization of Oxygen.

7. Peabody, Francis W., Sturgis, Cyrus C., with the assistance of Barker, Bertha I., and Reed, Margaret N.: Arch. Int. Med., 1922, xxix, 277. The Effect of Exercise on the Metabolism, Heart Rate and Pulmonary Ventilation of Normal Subjects and Patients with Heart Disease.

8. Smith, Henry M.: Carnegie Inst. Wash. Pub. No. 309, 1922. Gaseous Exchange and Physiological Requirements for Level and Grade Walking.

9. Strouse, Solomon, Wang, C. C., and Owen, Zelma: Jour. Clin. Invest., 1925, i, 586. Energy Expenditure during Mechanical Work in Obese, Normal and Thin People.

10. West, Howard F.: Arch. Int. Med., 1920, xxv, 306. A Comparison of Various Standards for the Normal Vital Capacity of the Lungs. 